\title{
Evaluation of unhealthy cervix by Pap smear and colposcopy guided biopsy
}

\author{
Meenakshi Venkatesh*, Ushadevi Gopalan
}

Department of Obstetrics and Gynecology, Shri Sathya Sai Medical College and Research Institute, Tamil Nadu, India

Received: 27 March 2020

Accepted: 29 April 2020

\section{*Correspondence:}

Dr. Meenakshi Venkatesh,

E-mail: meenakshisevu@gmail.com

Copyright: (C) the author(s), publisher and licensee Medip Academy. This is an open-access article distributed under the terms of the Creative Commons Attribution Non-Commercial License, which permits unrestricted non-commercial use, distribution, and reproduction in any medium, provided the original work is properly cited.

\section{ABSTRACT}

Cancer of cervix ranks as the third common malignancy in females worldwide. In developing countries like India, carcinoma cervix is the second commonest malignancy affecting females. India accounts for 18\% of the global burden of carcinoma cervix. To address the above problem a literature review was done using search engines like PubMed, Google scholar etc to evaluate the unhealthy cervix by comparison of Pap smear and colposcopy guided biopsy.

Keywords: Cervical carcinoma, Colposcopy guided biopsy, Pap smear and unhealthy cervix

\section{INTRODUCTION}

Cancer of cervix ranks as the third common malignancy in females worldwide. ${ }^{1}$ India accounts for $18 \%$ of the global burden of carcinoma cervix. ${ }^{2}$ In India, every year $1,26,000$ new cases are identified and 67,477 deaths occur due to cervical carcinoma. ${ }^{3}$ It was estimated worldwide that every $5^{\text {th }}$ women, who suffer from cervical cancer belongs to India. ${ }^{4}$

In developing countries like India, more than $70 \%$ of the population lives in rural areas. Rural Indian women undergo early marriage, multiple childbirth, poor nutrition status and they lack awareness about contraception, availability of screening programmes and therefore are prone to acquire carcinoma cervix. ${ }^{5} 65 \%$ of cervical carcinoma occurs in rural Indian women. ${ }^{6}$ Only $10-15 \%$ of the general population are aware of screening facilities available.

In India, only $2.6-5 \%$ of women undergo screening. ${ }^{4}$ According to the National Institute of Cancer Prevention and Research, one woman dies of cervical carcinoma every $8^{\text {th }}$ minute in India. ${ }^{7}$
Cervical cancer is a malignancy that has got a long latent period to transform into invasive carcinoma, so if women undergo screening at an early stage of disease, invasive lesion of cervix can be prevented. ${ }^{6}$ More than $80 \%$ of women with cervical carcinoma present with advanced stage of disease, due to their lack of health education, awareness of screening programs and lack of accessibility to medical services. ${ }^{9}$

Papanicolaou (Pap) smear is a simple, cheap and noninvasive method used for screening of carcinoma cervix, with specificity of $94 \%$ and sensitivity of $72 \% .^{9}$ Pap smear requires laboratory facilities, infrastructure and cytologist to interpret the reports.

Hence, it is not suitable for a place with low resource setting. Therefore, down staging with visual inspection of the cervix with acetic acid (VIA) and visual inspection with Lugol's iodine (VILI) is performed to detect early lesions of cervix. ${ }^{9}$

\section{Study design}

A narrative review of published literature. 


\section{Materials and methods}

Authors conducted a comprehensive literature research to identify all the published studies evaluating the unhealthy cervix by comparing Pap smear and colposcopy guided biopsy. A combination of keywords was used to identify the maximum number of relevant citations in PubMed, Google scholar from 2015 to 2020 by typing the key words cervical carcinoma, colposcopy guided biopsy and Pap smear.

\section{REVIEW OF LITERATURE}

A study was conducted by Vidya et al on 300 women of reproductive age group. $88 \%$ had inflammatory smear, ASCUS in $5 \%$, LSIL in $1.4 \%$, HSIL in $0.3 \%$ and invasive carcinoma in $0.3 \%$ patients. Cervix biopsy was done in 13 patients, out of which 12 had cervicitis and 1 had CIN. ${ }^{2}$ Study concluded that, although Pap smear has poor sensitivity in detecting cervical lesions, it serves as a simple, safe and non-invasive method of detecting precursor lesions of carcinoma cervix. ${ }^{3}$

A study was conducted by Sinha et al on 200 women attending gynecology OPD. All these women were subjected to combined screening methods Pap smear, VIA and VILI. Cervix biopsy was taken from suspicious areas found in VIA/VILI. This study concludes that combined screening methods had higher sensitivity rate of $88.23 \%$ and a specificity rate of $76.68 \%$. $^{5}$

A cross-sectional study was conducted by Vidyadhar et al in a tertiary care hospital in Barabanki. Pap smear has good specificity of $94.4 \%$, and colposcopy has good sensitivity of $85.9 \%$, so both these tests can be used for detection of cervical lesions. ${ }^{8}$

Das et al conducted a study in a tertiary care hospital. Pap smear was taken from 5025 women who participated in this study. $44.64 \%$ of women had premalignant lesions and $43.94 \%$ women of age 51-60 years had carcinoma cervix. Study concludes that proper implementation of Pap smear as a screening tool can reduce the incidence of cervical carcinoma. ${ }^{9}$

\section{DISCUSSION}

This study included 110 women in which $42.7 \%$ women belonged to age group 31-40 years, which is comparable to the study by Kalyankar et al $(39.7 \%) .{ }^{1}$ The findings in their studies could be different from the present study because their study sample was more compared to this study.

In this study, $22.72 \%$ of women in the age group of $31-40$ years had inflammatory Pap smear. In the age groups, 3140 years, 41-50 years and 51-60 years, LSIL was found in $1.8 \%$ of women in each age group. In the age groups, 4150 years and 51-60 years, HSIL was seen in $1.8 \%$ of women in each age group. Also, 1.8\% (2 women) had squamous cell carcinoma in this study. In these two women, one belonged to the age group 41-50 years and another woman belonged to the age group 51-60 years. Both these women were multiparous, had early marriage and belonged to low socio-economic class. Thus, these two women had multiple high-risk factors for developing carcinoma cervix.

In this study, $38.2 \%$ of women were multiparous, which is comparable to the study by Kalyankar et al in which, $38.2 \%$ women were multiparous. ${ }^{1}$ In this study, white discharge was the most common complaint (46.4\%), followed by lower abdominal pain $(24.5 \%)$, postcoital bleeding (10\%) and post-menopausal bleeding (8.2\%), which is similar to the study by Kalyankar et al and Garg et al, seen in $36.5 \% .^{1,2}$ These variations could be due to differences in ethnicity and study population.

In this study, 2 women (1.8\%) had carcinoma cervix. They were multiparous women, belonging to low socioeconomic group. Among them, one woman presented with post coital bleeding and another women presented with postmenopausal bleeding. These are the most common symptoms of carcinoma cervix. In this study, on per speculum examination, $29.1 \%$ of women had white discharge, followed by cervical erosion in $19.1 \%$, hypertrophied cervix in $18.2 \%$, congested cervix in $14.5 \%$, cervical erosion that bleeds on touch in $11.8 \%$ and cervix with foul smelling discharge that bleeds on touch in $7.3 \%$ women.

A study by Kalyankar et al, found cervical erosion in $30.61 \%$, ectropion in $14.28 \%$, congested cervix in $6.12 \%$ and leukoplakia in $1.02 \% .^{1}$ In this study, on Pap smear examination, authors found that $34.5 \%$ had normal Pap smear, 53.6\% had inflammatory Pap smear, $0.1 \%$ had bacterial vaginosis, $6.4 \%$ had LSIL and $4.5 \%$ had HSIL. These differences may be due to differences in study population, observer errors, and also due to the fact that in this study, most of the women belonged to low socioeconomic class and hence, are more prone to infection and develop carcinoma cervix.

\section{Implication in practice}

Cervix biopsy is gold standard in detection of carcinoma cervix. women with abnormal Pap smear, should be subjected to cervix biopsy, in order to detect carcinoma cervix at earlier stage.

\section{CONCLUSION}

From the above study analysis, it is concluded that Pap smear is a screening method and cervix biopsy is gold standard in detection of carcinoma cervix.

Funding: No funding sources

Conflict of interest: None declared

Ethical approval: Not required 


\section{REFERENCES}

1. Kalyankar VY, Kalyankar BV, Gadappa SN, Kute S. Colposcopic evaluation of unhealthy cervix and it's correlation with Papanicolau smear in cervical cancer screening. Int J Reprod Contracept Obstet Gynecol. 2017;6:4959-65.

2. Garg R, Desai R. Cytologic and colposcopic evaluation of all symptomatic women at tertiary care centre. Int J Adv Med. 2017;4:799-80.

3. Thobbi VA, Khan F. Cervical cytology by Pap smear in reproductive population. Int $\mathrm{J}$ Reprod Contracept Obstet Gynecol. 2018;7:1988-92.

4. Sharma JC, Leekha K. Awareness, positivity of Pap smear in adult females. Indian $\mathbf{J}$ Gynecol Oncol. 2018;16(3):46.

5. Sinha S, Singh V, Mishra B, Singh A. Comparing the efficacy of visual inspection of cervix with acetic acid and Lugol's iodine with Pap smear cytology in screening for cancer cervix. J Cur Res Scient Med. 2018;4(1):10.

6. Rajendiran S, Gopalan U, Karnaboopathy R. Evaluation of histopathology of cervix in women with unhealthy cervix. Int $\mathrm{J}$ Reprod Contracept Obstet Gynecol. 2017;6(3):842-5.
7. Narayana G, Suchitra MJ, Sunanda G, Ramaiah JD, Kumar BP, Veerabhadrappa KV. Knowledge, attitude, and practice toward cervical cancer among women attending obstetrics and gynecology department: a cross-sectional, hospital-based survey in South India. Indian J Cancer. 2017;54(2):481.

8. Vidyadhar DS, Bhattacharya DA, Bohara DS, Dwivedi DA, Agarwal DA, Gangwar DD. Comparison and correlation of cytology, colposcopy and histopathology of premalignant lesions of cervix in rural women of Barabanki District. IOSR J Dent Med Sci. 2017;16(4):13-8.

9. Das D, Kar A, Rath S, Baliarsingh SK, Prusty D, Dash AK. Cytological pattern of papanicolaou smears and detection of cervical cancers: an experience from a tertiary care center of eastern zone of India. Oncol J India. 2018;2(2):25.

Cite this article as: Venkatesh M, Gopalan U. Evaluation of unhealthy cervix by Pap smear and colposcopy guided biopsy. Int J Reprod Contracept Obstet Gynecol 2020;9:2663-5. 